\title{
Hexagonal boron nitride nanosheets incorporated antireflective silica coating with enhanced laser-induced damage threshold
}

\author{
Jing Wang ${ }^{1,3,4}$, Chunhong $\mathrm{Li}^{2}$, Wenjie $\mathrm{Hu}^{3}$, Wei $\mathrm{Han}^{2}$, Qihua $\mathrm{Zhu}^{2}$, and Yao $\mathrm{Xu}^{3}$ \\ ${ }^{1}$ Institute of Coal Chemistry, Chinese Academy of Sciences, Taiyuan 030001, China \\ ${ }^{2}$ Research Center of Laser Fusion, China Academy of Engineering Physics, Mianyang 621900, China \\ ${ }^{3}$ State Key Laboratory of Transient Optics and Photonics, Xi'an Institute of Optics and Precision Mechanics, Chinese Academy of \\ Sciences, Xi'an 710119, China \\ ${ }^{4}$ University of Chinese Academy of Sciences, Beijing 100049, China \\ (Received 30 November 2017; revised 2 January 2018; accepted 7 March 2018)
}

\begin{abstract}
Boron nitride $(\mathrm{BN})$ nanosheets incorporated silica antireflective (AR) coating was successfully prepared on fused silica substrate to improve the antilaser-damage ability of transmissive optics used in high-power laser systems. The BN nanosheets were obtained by urea assisted solid exfoliation, and then incorporated into basic-catalyzed silica sols without any further treatment. The transmission electron microscope (TEM) images indicated that the BN nanosheets generally consisted of 2-10 layers. The antireflective $\mathrm{BN} / \mathrm{SiO}_{2}$ coating exhibited excellent transmittance as high as $99.89 \%$ at $351 \mathrm{~nm}$ wavelength on fused silica substrate. The thermal conductivity $0.135 \mathrm{~W} \cdot \mathrm{m}^{-1} \cdot \mathrm{K}^{-1}$ of the $\mathrm{BN} / \mathrm{SiO}_{2}$ coating with $10 \% \mathrm{BN}$ addition was about $23 \%$ higher than $0.11 \mathrm{~W} \cdot \mathrm{m}^{-1} \cdot \mathrm{K}^{-1}$ of the pure $\mathrm{SiO}_{2} \mathrm{AR}$ coating. The laser-induced damage threshold (LIDT) of that $\mathrm{BN} / \mathrm{SiO}_{2}$ coating is also $23.1 \%$ higher than that of pure $\mathrm{SiO}_{2} \mathrm{AR}$ coating. This research provides a potential application of $\mathrm{BN} / \mathrm{SiO}_{2}$ coatings in high-power laser systems.
\end{abstract}

Keywords: hexagonal boron nitride; laser-induced damage; silica antireflective coating; thermal conductivity

\section{Introduction}

Antireflective (AR) coating is an important type of optical coating applied to the surface of transparent optical elements to reduce reflection. In high-power laser systems, laserinduced damage of the optical coating is the most important factor that limits the further development of high-power laser ${ }^{[1]}$. Low laser-induced damage threshold (LIDT) not only reduces the laser beam quality, but leads to explosion of optical elements in vacuum. More and more attention is being paid to enhance LIDT of AR coating with the increase of laser power density. For this end, it is necessary to improve the surface quality of substrate and the interface energy diffusion between coating and substrate. The most frequently used methods for polishing substrate include ultrasonic cleaning, fine abrasive liquid polishing and super-polishing ${ }^{[2-4]}$. On the other hand, the current experimental results indicate that microdefect and

Correspondence to: Y. Xu, State Key Laboratory of Transient Optics and Photonics, Xi' an Institute of Optics and Precision Mechanics, Chinese Academy of Sciences, Xi'an 710119, China. Email: xuyao@opt.ac.cn absorption of the coating are the major factors that influence the quality of coating. To reduce microdefect density and absorption, and improve LIDT of coating, researchers have developed many methods, such as laser conditioning, ion post-treatment $^{[5]}$, effective cleaning process ${ }^{[6]}$, modifying sols $^{[7]}$ and maintaining pressures ${ }^{[8]}$ and temperature during deposition $^{[9]}$. Silica AR coatings prepared by the solgel method have been widely used in high-power laser systems owing to its excellent optical performance, low cost, thermal mechanical properties and relatively high LIDT $^{[10-13]}$. The common method of improving the quality of AR coating is to modify silica sol with polyvinyl butyral $(\mathrm{PVB})^{[14]}$ or polyvinylpyrrolidone (PVP) ${ }^{[15]}$. However, the addition of PVB and PVP into the silica sol decreases the porosity of coating, therefore, the refractive index of coating increases and the transmittance of coating decreases to $98 \%$. Moreover, both of the methods are complex, and the thermal treatment of coating is needed. Hexagonal boron nitride (h-BN), a graphite-like inorganic compound composed of boron and nitrogen atoms in a hexagonal arrangement, has got recent attention ${ }^{[16,17]}$. Combining the high thermal 
conductivity $\left(\sim 280 \mathrm{~W} \cdot \mathrm{m}^{-1} \cdot \mathrm{K}^{-1}\right.$ in plane $)$ and excellent electrical insulation, $\mathrm{BN}$ is a promising filler to enhance the thermal conductivity and retain the insulation of materials ${ }^{[18]}$. In addition, it is also noted that BN nanosheets exhibit high optical transmittance in ultraviolet, visible and nearinfrared bands ${ }^{[19]}$. In recent years, many efforts have been made to fabricate low cost and high activity materials by incorporating silicon with $\mathrm{BN}^{[20,21]}$. If $\mathrm{BN}$ nanosheets can be combined with silica coating, they may create a high LIDT AR coating.

\section{Working principle}

In this paper, $\mathrm{BN} / \mathrm{SiO}_{2} \mathrm{AR}$ coating was successfully prepared by $\mathrm{BN}$-incorporated $\mathrm{SiO}_{2}$ sol. First, the $\mathrm{BN}$ nanosheets suspension was prepared by urea assisted solid exfoliation. Hexagonal boron nitride (Sinopharm Chemical, 98\%) and urea (Sinopharm Chemical, 99.0\%) were mixed in an agate milling container with the mass ratio of 1:60 and milled at a rotation speed of $600 \mathrm{r} \cdot \mathrm{min}^{-1}$ for $48 \mathrm{~h}$ at room temperature. After ball milling, urea was removed through dialysis with deionized water for several times. In this process, fewlayer BN nanosheets can readily be dispersed in water with sonication. After the water was evaporated, the solid product was redissolved in ethanol (Sinopharm Chemical, 99.7\%), forming homogeneous BN nanosheets ethanol suspension. The concentration of $\mathrm{BN}$ nanosheets ethanol suspension was $0.2 \mathrm{mg} \cdot \mathrm{mL}^{-1}$. The $\mathrm{SiO}_{2}$ sol was prepared using tetraethyl orthosilicate (TEOS, ACROS, 98\%) as precursor, ammonia (Sinopharm Chemical, 25\%-28\%) as catalyst and ethanol as solvent. The final molar ratio of $\mathrm{SiO}_{2}$ sol was TEOS/ammonia/ $\mathrm{H}_{2} \mathrm{O} /$ ethanol $=1: 0.57: 2.45: 38$. The $\mathrm{SiO}_{2}$ sol was stirred for $24 \mathrm{~h}$ and then aged for more than 7 days at room temperature. The $\mathrm{BN} / \mathrm{SiO}_{2}$ sols were prepared by adding $\mathrm{BN}$ nanosheets ethanol suspension into $\mathrm{SiO}_{2}$ sol to form a mixture with $10 \mathrm{wt} \%$ or $20 \mathrm{wt} \%$ of $\mathrm{BN}$ nanosheets ethanol suspension. Then the $\mathrm{BN} / \mathrm{SiO}_{2}$ sols were sonicated for $20 \mathrm{~min}$ at room temperature. The final sols were accordingly marked as $10 \mathrm{wt} \% \mathrm{BN} / \mathrm{SiO}_{2}$ sol and $20 \mathrm{wt} \%$ $\mathrm{BN} / \mathrm{SiO}_{2}$ sol, the concentration of $\mathrm{BN}$ nanosheets was $0.02 \mathrm{mg} \cdot \mathrm{mL}^{-1}$ in $10 \mathrm{wt} \% \mathrm{BN} / \mathrm{SiO}_{2}$ sol and $0.04 \mathrm{mg} \cdot \mathrm{mL}^{-1}$ in $20 \mathrm{wt} \% \mathrm{BN} / \mathrm{SiO}_{2}$ sol. The $\mathrm{BN} / \mathrm{SiO}_{2}$ AR coatings were deposited via dip-coating on well-polished and well-cleaned fused silica (Heraeus 312) substrates which were named $\mathrm{SiO}_{2}$ coating, $10 \mathrm{wt} \% \mathrm{BN} / \mathrm{SiO}_{2}$ coating and $20 \mathrm{wt} \% \mathrm{BN} / \mathrm{SiO}_{2}$ coating.

The exfoliation process assisted by urea generated functional amino groups at defective sites and edges of $\mathrm{BN}$ (002) planes that made the $\mathrm{BN}$ nanosheets suspension more stable ${ }^{[22]}$. The left inset of Figure 1(a) shows a milky appearance of BN nanosheets water suspension, the concentration up to $1.0 \mathrm{mg} \cdot \mathrm{mL}^{-1}$. After replacing the water with ethanol, the $\mathrm{BN}$ nanosheets ethanol suspension was very stable over several months under ambient conditions in a sealed bottle.
In the right inset of Figure 1(a), the BN nanosheets ethanol suspension displays an obvious Tyndall effect due to the light scattering by BN nanosheets. Figure 1(a) also shows the distinct absorption peak at $204 \mathrm{~nm}(6.08 \mathrm{eV})$ which is attributed to the intrinsic exciton absorption band of $\mathrm{BN}$ nanosheets. The structure of BN nanosheets was also investigated by X-ray diffraction (XRD, Bruker D2). As shown in Figure 1(b), five peaks can be observed at $26.4^{\circ}$, $41.4^{\circ}, 43.5^{\circ}, 49.0^{\circ}$ and $54.6^{\circ}$, corresponding to the (002), (100), (101), (102) and (004) planes of h-BN. Clearly, the (002) and (004) diffraction peaks of $\mathrm{BN}$ nanosheets became much stronger compared with the (100), (101), (102) peaks, which might be attributed to the enhanced exposure of (002) and (004) planes upon exfoliation, indicating BN nanosheets were peeled off along the (002) and (004) planes without considerable destroy of crystalline structure. The morphology of BN nanosheets was tested by a transmission electron microscope (HRTEM, JEOL-2100). TEM image of $\mathrm{BN}$ nanosheets shows that the BN nanosheets were flat and quite thin and the lateral sizes were $500-1000 \mathrm{~nm}$, suggesting that the $\mathrm{BN}$ nanosheets remain intact and are not broken down by ball exfoliation. From Figure 1(d), HRTEM image at the edges of $\mathrm{BN}$ nanosheets clearly shows the thicknesses of BN nanosheets were significantly reduced. The layer numbers of obtained BN nanosheets were 2-10, corresponding to the thickness of 1-4 nm. Incorporation of such thinner $\mathrm{BN}$ nanosheets into $\mathrm{SiO}_{2}$ sols may have little influence on transmittance of $\mathrm{SiO}_{2}$ AR coating.

The detailed dispersion of $\mathrm{BN}$ nanosheets in the $\mathrm{BN} / \mathrm{SiO}_{2}$ coating was characterized by Raman spectroscopy mapping technology (RAMANforce, Nanophoton Corporation) at a laser wavelength of $532 \mathrm{~nm}$. Figure 2(a) shows the Raman mapping of $10 \mathrm{wt} \% \mathrm{BN} / \mathrm{SiO}_{2}$ coating and the green dots display the locations of $\mathrm{BN}$ nanosheets and indicates the $\mathrm{BN}$ nanosheets are uniformly distributed in the $\mathrm{BN} / \mathrm{SiO}_{2}$ coating. Figure 2(b) shows the Raman spectrum of area (1) in the mapping image. Only the typical peak of $E_{2 g}$ mode can be found at $\sim 1366 \mathrm{~cm}^{-1}$, indicating few-layer $\mathrm{BN}$ nanosheets were present in the $\mathrm{BN} / \mathrm{SiO}_{2}$ coating. Figure 2(c) shows the TEM image of $10 \mathrm{wt} \% \mathrm{BN} / \mathrm{SiO}_{2}$ sol, in which the $\mathrm{SiO}_{2}$ particles were uniformly distributed on the $\mathrm{BN}$ nanosheets. That is consistent with the Raman-mapping result. The inset in Figure 2(c) shows the uniform particle size distribution of $\mathrm{SiO}_{2}$ particles with diameter of about $10 \mathrm{~nm}$, which determined the antireflection at $351 \mathrm{~nm}$ wavelength of $\mathrm{BN} / \mathrm{SiO}_{2}$ coating ${ }^{[23]}$. Figure 2(d) shows the HRTEM image of the $10 \mathrm{wt} \% \mathrm{BN} / \mathrm{SiO}_{2}$ sol, in which the $\mathrm{BN}$ nanosheets can be clearly seen between several $\mathrm{SiO}_{2}$ particles.

The surface morphology of $\mathrm{BN} / \mathrm{SiO}_{2}$ coating was confirmed by atomic-force microscopy (AFM) (Innova, Bruker). In order to obtain the more precise roughness values, each coating was measured at ten points of random selection and finally the average was taken. Figure 3 shows the AFM images of bare fused silica substrate, $\mathrm{SiO}_{2}$ coating, $10 \mathrm{wt} \%$ $\mathrm{BN} / \mathrm{SiO}_{2}$ coating and $20 \mathrm{wt} \% \mathrm{BN} / \mathrm{SiO}_{2}$ coating which were 


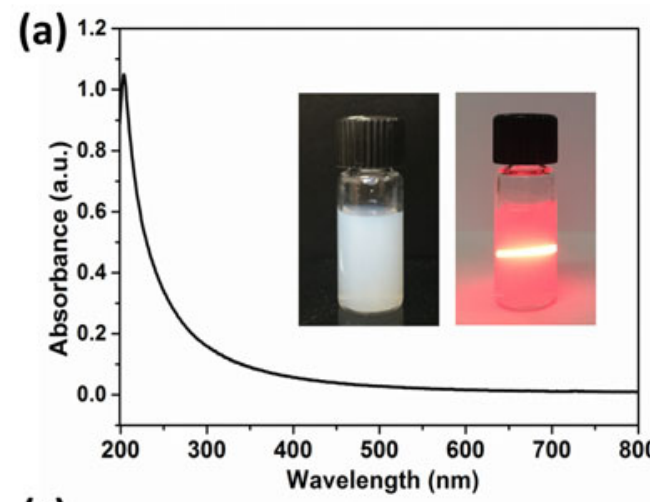

(c)

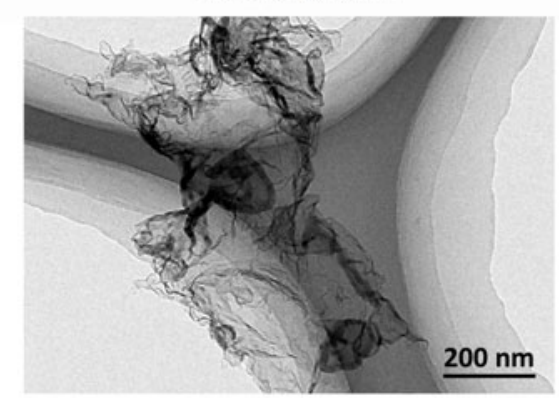

(b)

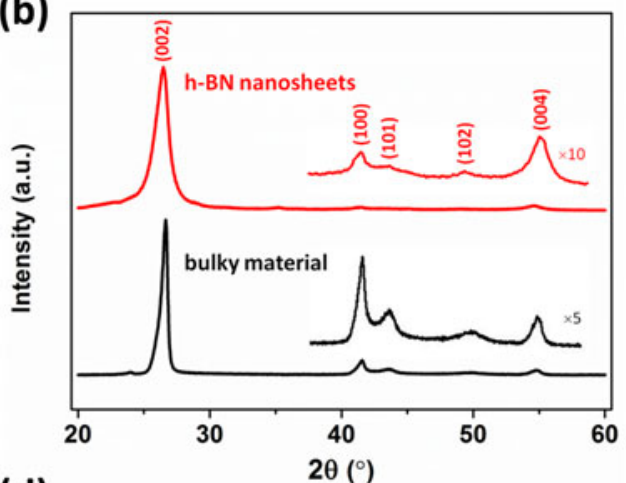

(d)

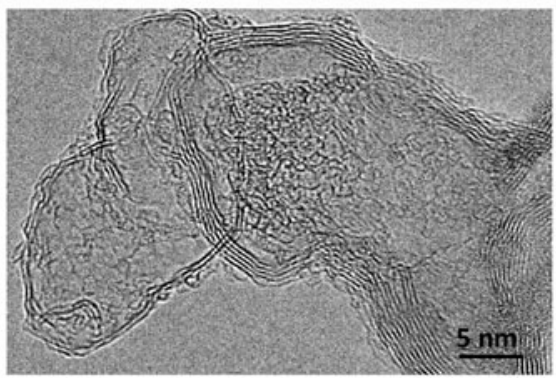

Figure 1. (a) Optical absorption of BN nanosheets dispersion in ethanol. Inset: photographs of BN nanosheets dispersion in water (left) and ethanol (right). (b) XRD patterns of BN nanosheets we used here and h-BN bulky material. Inset: the curves in the region of $37^{\circ}-57^{\circ}$. (c) TEM and (d) HRTEM images of BN nanosheets.

(a)

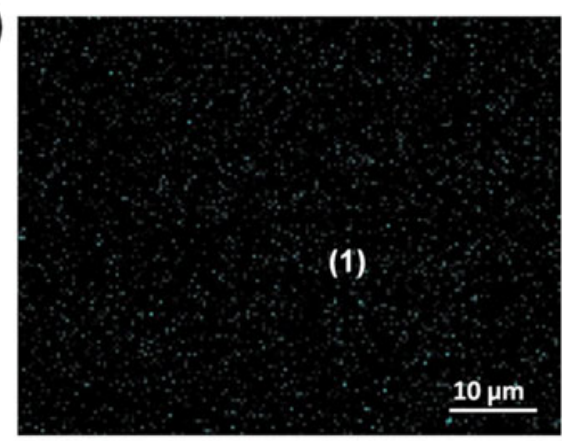

(c)

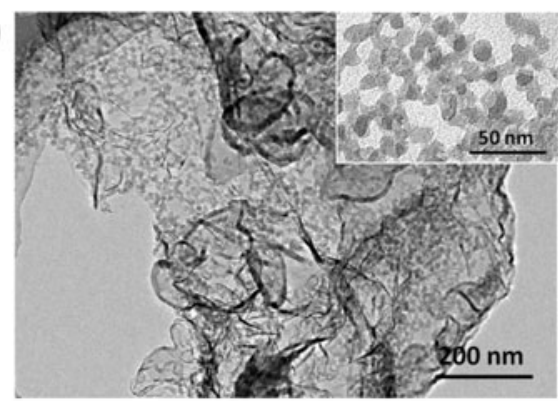

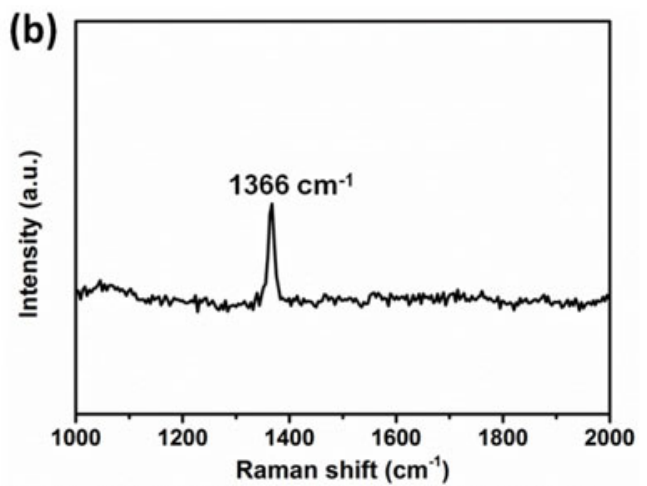

(d)

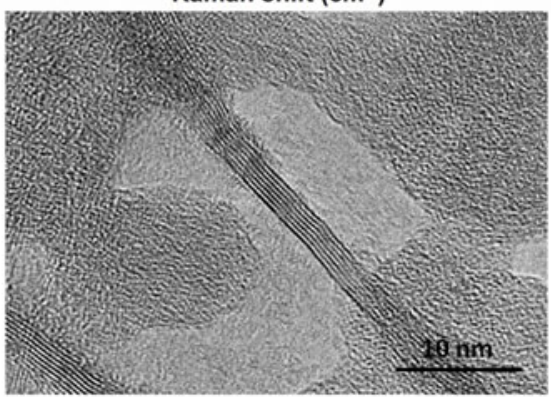

Figure 2. (a) Raman-mapping image of $10 \mathrm{wt} \% \mathrm{BN} / \mathrm{SiO}_{2}$ coating: green dots are $\mathrm{BN}$ nanosheets. (b) The Raman spectrum of area (1) in the mapping. (c) TEM image of $10 \mathrm{wt} \% \mathrm{BN} / \mathrm{SiO}_{2}$ sol. Inset: TEM image of $\mathrm{SiO}_{2}$ particles. (d) HRTEM image of $\mathrm{BN}$ nanosheets in the $10 \mathrm{wt} \% \mathrm{BN} / \mathrm{SiO}_{2}$ sol. 

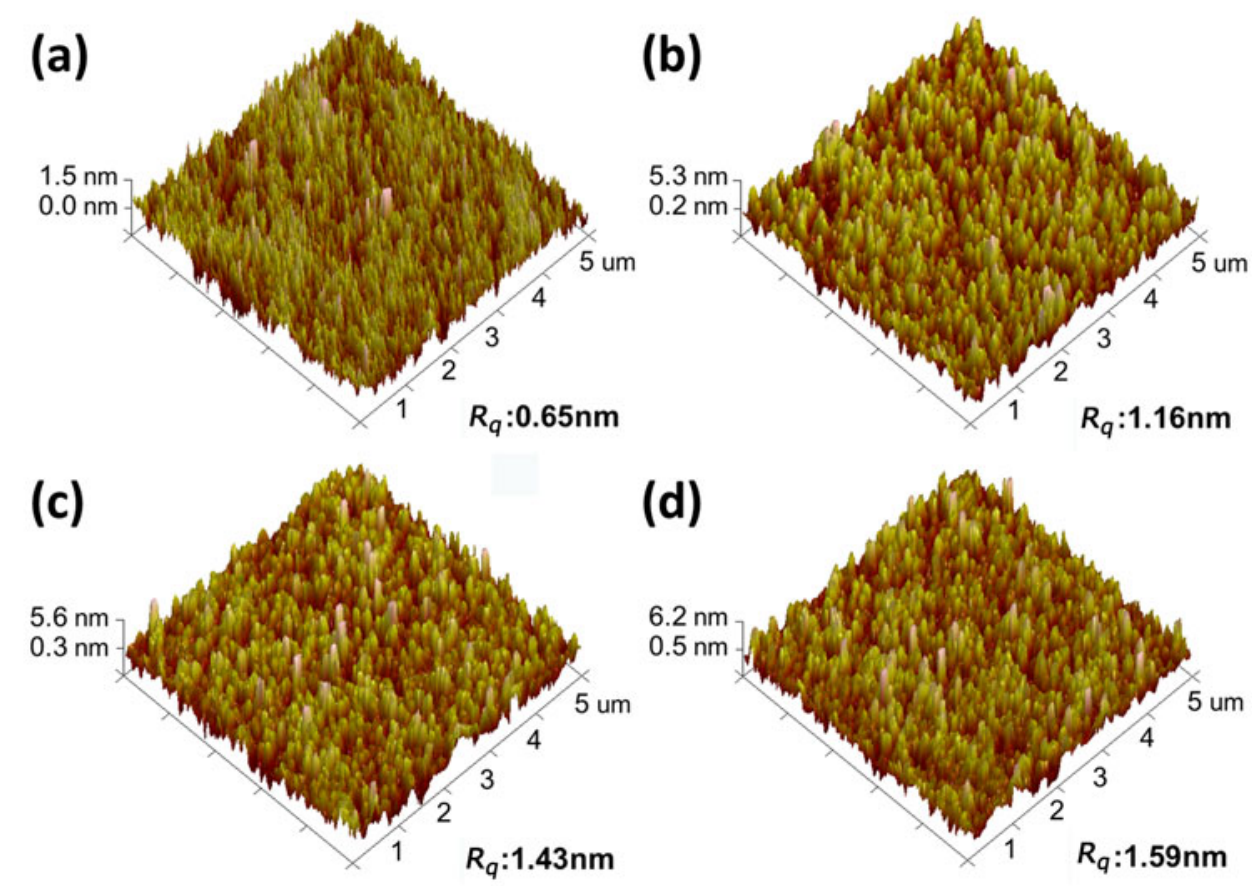

Figure 3. AFM images of (a) bare fused silica substrate, (b) $\mathrm{SiO}_{2}$ coating, (c) $10 \mathrm{wt} \% \mathrm{BN} / \mathrm{SiO}_{2}$ coating and (d) $20 \mathrm{wt} \% \mathrm{BN} / \mathrm{SiO}_{2}$ coating.

randomly selected from obtained images. The root-meansquare roughness $\left(R_{q}\right)$ values of coatings were calculated using the AFM images. As BN nanosheets were incorporated into $\mathrm{SiO}_{2}$ sols, the $R_{q}$ values show a small increase for $10 \mathrm{wt} \% \mathrm{BN} / \mathrm{SiO}_{2}$ coating and $20 \mathrm{wt} \% \mathrm{BN} / \mathrm{SiO}_{2}$ coating. Because the $R_{q}$ values of all the $\mathrm{BN} / \mathrm{SiO}_{2}$ coatings were less than $2 \mathrm{~nm}$, the surface scattering of coating was small enough to avoid additional decrease in transmittance. Meanwhile, there is little difference in $R_{q}$ between $10 \mathrm{wt} \% \mathrm{BN} / \mathrm{SiO}_{2}$ coating and $20 \mathrm{wt} \% \mathrm{BN} / \mathrm{SiO}_{2}$ coating, which indicates the lateral sizes and thicknesses of $\mathrm{BN}$ nanosheets were suitable for preparing $\mathrm{BN} / \mathrm{SiO}_{2} \mathrm{AR}$ coating. Both $\mathrm{AFM}$ and TEM results were mutually complementary and offered a very detailed analysis of $\mathrm{BN} / \mathrm{SiO}_{2}$ coatings.

In order to investigate the optical property of $\mathrm{BN} / \mathrm{SiO}_{2} \mathrm{AR}$ coating, fused silica substrates were coated by dipping into the $\mathrm{SiO}_{2}$ sol, $10 \mathrm{wt} \% \mathrm{BN} / \mathrm{SiO}_{2}$ sol and $20 \mathrm{wt} \% \mathrm{BN} / \mathrm{SiO}_{2}$ sol. The refractive index and thickness of AR coatings were calculated using a spectroscopic ellipsometer (SC620, Sanco) at $60^{\circ}$ incidence, and listed in Table 1 . The optical thickness of coating was controlled to match the desired antireflective wavelength $351 \mathrm{~nm}$ by adjusting the dipping speed. The optical transmittance results were measured by a UV-VisNIR spectrometer (U-4100, Hitachi) in the wavelength range from 200 to $800 \mathrm{~nm}$. Figure 4 shows the transmittance spectra of $\mathrm{SiO}_{2}$ coating, $10 \mathrm{wt} \% \mathrm{BN} / \mathrm{SiO}_{2}$ coating and $20 \mathrm{wt} \%$ $\mathrm{BN} / \mathrm{SiO}_{2}$ coating. As shown in Table 1 , the maximum transmittances of $\mathrm{SiO}_{2}$ coating, $10 \mathrm{wt} \% \mathrm{BN} / \mathrm{SiO}_{2}$ coating and $20 \mathrm{wt} \% \mathrm{BN} / \mathrm{SiO}_{2}$ coating are all over $99.8 \%$ at $351 \mathrm{~nm}$, which is an excellent antireflective performance for applying in

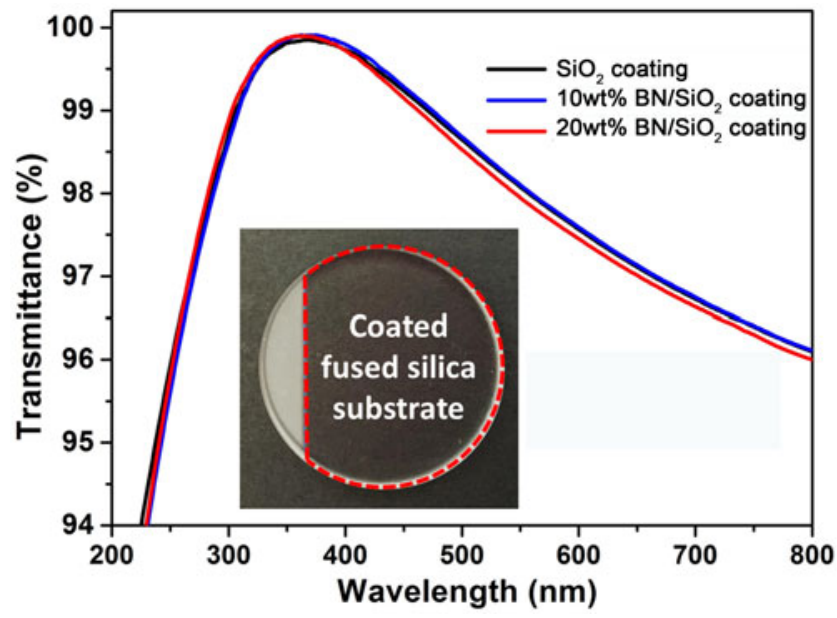

Figure 4. Transmittance of $\mathrm{SiO}_{2}$ coating, $10 \mathrm{wt} \% \mathrm{BN} / \mathrm{SiO}_{2}$ coating and $20 \mathrm{wt} \% \mathrm{BN} / \mathrm{SiO}_{2}$ coating. The inset is the photograph of $10 \mathrm{wt} \% \mathrm{BN} / \mathrm{SiO}_{2}$ coating on fused silica substrate to show the high transmittance.

high-power laser systems. Almost the same transmittance of coatings is mainly due to the high optical transmittance of $\mathrm{BN}$ nanosheets in ultraviolet, visible and near-infrared bands and the small concentration of BN nanosheets in sol which was too small to affect the transmittance of coating. The digital image of $10 \mathrm{wt} \% \mathrm{BN} / \mathrm{SiO}_{2}$ coating on fused silica substrate is shown in Figure 4, which indicates a significantly improved transmittance of $\mathrm{BN} / \mathrm{SiO}_{2}$ coating.

Laser-induced damage threshold test was performed via the 'R-on-1' mode according to ISO standard 11254-2: 2000, 


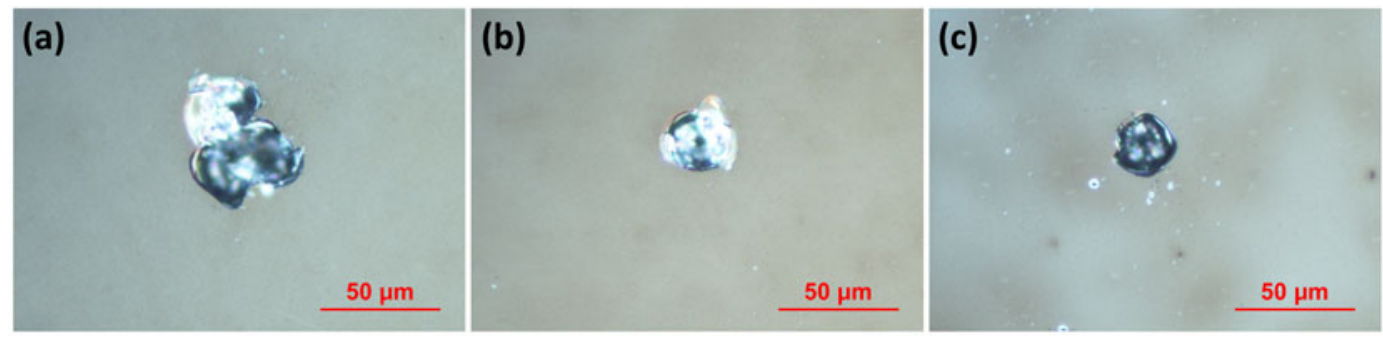

Figure 5. Laser-induced damage morphologies of AR coatings (a) $\mathrm{SiO}_{2}$ coating, (b) $10 \mathrm{wt} \% \mathrm{BN} / \mathrm{SiO}_{2}$ coating and (c) $20 \mathrm{wt} \% \mathrm{BN} / \mathrm{SiO}{ }_{2}$ coating.

Table 1. Optical parameters of $\mathrm{BN} / \mathrm{SiO}_{2}$ coatings with various $\mathrm{BN}$ nanosheets mass ratios.

\begin{tabular}{lccccc}
\hline Sample & $n_{f}$ & Thickness $(\mathrm{nm})$ & $T_{\max }(\%)$ & $R_{q}(\mathrm{~nm})$ & ${\text { Average LIDT }\left(\mathrm{J} \mathrm{cm}^{-2}\right)}^{-2}$ \\
\hline Bare fused silica substrate & 1.46 & - & 93.56 & 0.514 & 8.69 \\
$\mathrm{SiO}_{2}$ coating & 1.25 & 73 & 99.84 & 2.597 & 8.92 \\
$10 \mathrm{wt} \% \mathrm{BN} / \mathrm{SiO}_{2}$ coating & 1.24 & 75 & 99.89 & 3.740 & 10.98 \\
$20 \mathrm{wt} \% \mathrm{BN} / \mathrm{SiO}_{2}$ coating & 1.24 & 74 & 99.92 & 3.638 & 8.96 \\
\hline
\end{tabular}

$n_{f}$ is the refractive index of coating; $T_{\max }$ is the maximum transmittance at $351 \mathrm{~nm} ; R_{q}$ is the root-mean-square roughness value of coating; LIDT means laser-induced damage threshold with $6.60 \mathrm{~ns}$ pulse of $351 \mathrm{~nm}$ laser.

using a $351 \mathrm{~nm}$ pulse laser with a pulse width of $6.6 \mathrm{~ns}$ and the laser spot area of $1.02 \mathrm{~mm}^{2}$. The LIDT data of coatings are shown in Table 1. There was a small increase in the threshold from 8.69 to $8.92 \mathrm{~J} \cdot \mathrm{cm}^{-2}$ as the traditional $\mathrm{SiO}_{2}$ coating was deposited on the fused silica substrate. Under laser irradiation, the coating was destroyed when the surface temperature increased to the melting point after the laser energy was absorbed by coating. The LIDT result of $10 \mathrm{wt} \%$ $\mathrm{BN} / \mathrm{SiO}_{2}$ coating is significantly higher than that of bare $\mathrm{SiO}_{2}$ coating on fused silica substrate, especially the $10 \mathrm{wt} \%$ $\mathrm{BN} / \mathrm{SiO}_{2}$ coating shows $23.1 \%$ increase of LIDT without any other treatment. The enhanced LIDT of $20 \mathrm{wt} \% \mathrm{BN} / \mathrm{SiO}_{2}$ coating is only $8.96 \mathrm{~J} \cdot \mathrm{cm}^{-2}$, which is much smaller than that of $10 \mathrm{wt} \% \mathrm{BN} / \mathrm{SiO}_{2}$ coating.

In addition to the LIDT, damage morphology of coating was tested to analyze the laser damage mechanism of coating. Figure 5 shows the laser-induced damage morphology of $\mathrm{SiO}_{2}$ coating, $10 \mathrm{wt} \% \mathrm{BN} / \mathrm{SiO}_{2}$ coating and $20 \mathrm{wt} \% \mathrm{BN} / \mathrm{SiO}_{2}$ coating. As can be seen from Figures 5(a) and 5(b), the damage area of $10 \mathrm{wt} \% \mathrm{BN} / \mathrm{SiO}_{2}$ coating is smaller than that of the bare $\mathrm{SiO}_{2}$ coating, which indicates the $10 \mathrm{wt} \%$ $\mathrm{BN} / \mathrm{SiO}_{2}$ coating suffered the milder damage ${ }^{[14]}$. Seen from Figure 5(c), there are some tiny damage dots on the surface of $20 \mathrm{wt} \% \mathrm{BN} / \mathrm{SiO}_{2}$ coating. This may be attributed to plenty of $\mathrm{BN}$ nanosheets in coating, the more $\mathrm{BN}$ nanosheets in coating, the worse adhesion of coating would be.

As an excellent thermally conductive material, $\mathrm{BN}$ has been used to prepare electron-insulative and thermally conductive composites. Sato et al. ${ }^{[24]}$ prepared an h-BN/ polyimide composite film with high thermal conductivity up to $7 \mathrm{~W} \cdot \mathrm{m}^{-1} \cdot \mathrm{K}^{-1}$, in which the active edge planes of h-BN filler most probably interacted chemically with the surrounding polyimide matrix. The enhanced interactions resulted in fewer flaws, coherent interfaces and minimal interfacial phonon scattering. Zhou and co-workers ${ }^{[25]}$ reported a thermally conductive silicone rubber used BN powder as conductive fillers. The inclusion of $\mathrm{BN}$ increases both thermal conductivity and thermal stability, while decreases the coefficient of thermal expansion. Cho et al. ${ }^{[26]}$ reported a facile technique that modified BN nanosheets with iron oxides in order to fabricate highly oriented polysiloxane/BN nanosheet composite films. The thermal property of polysiloxane/BN nanosheet composite film was determined by the orientation of $\mathrm{BN}$, and the thermal conductivity of composite film was enhanced by 20 times after addition of $\mathrm{BN}$ nanosheets.

Here, BN nanosheets played an important role in enhancing the diffusion of heat because of its extremely high inplane thermal conductivity and insulation, but low coefficient of thermal expansion and superior thermal stability ${ }^{[27,28]}$. Because traditional basic silica coating was porous, the absorbed thermal energy cannot effectively transfer through the separated silica particles and the surrounding voids. BN nanosheets have good thermal conductivity, so the thermal conductivity of $\mathrm{BN} / \mathrm{SiO}_{2}$ coating must be higher than that of the traditional basic silica coating. With the laser radiation, the $\mathrm{BN} / \mathrm{SiO}_{2}$ coating has good slow-release ability to the local strain caused by the absorbed laser energy. A laser thermal conductivity testing instrument (NanoTR, NETZSCH) was used to evaluate the thermal conductivity of $\mathrm{SiO}_{2}$ coating and $10 \mathrm{wt} \% \mathrm{BN} / \mathrm{SiO}_{2}$ coating. The thermal conductivity coefficient of $10 \mathrm{wt} \% \mathrm{BN} / \mathrm{SiO}_{2}$ coating is $0.135 \mathrm{~W} \cdot \mathrm{m}^{-1} \cdot \mathrm{K}^{-1}, 23 \%$ higher than $0.110 \mathrm{~W} \cdot \mathrm{m}^{-1} \cdot \mathrm{K}^{-1}$ of bare $\mathrm{SiO}_{2}$ coating, which was consistent with the increased LIDT.

In summary, the antireflective $\mathrm{BN} / \mathrm{SiO}_{2}$ coatings have been successfully prepared through incorporating BN nanosheets 
into traditional basic silica sol without any additional treatment. The $\mathrm{BN} / \mathrm{SiO}_{2}$ coatings revealed very promising antireflective properties at $351 \mathrm{~nm}$ and also enhanced LIDT performance. This is a good candidate for the future application of AR coating in optical components for a high-power laser system. In contrast with other modifying silica sol methods, this work has very low cost and simple process. By optimizing the content of BN nanosheets, coating material, and other design parameters, the antilaser-damage ability may be further enhanced.

\section{Acknowledgement}

This work was supported by National Natural Science Foundation of China (Nos. U1530148 and 61605188).

\section{References}

1. N. Bloembergen, Appl. Opt. 12, 661 (1973).

2. B. Bertussi, J.-Y. Natoli, and M. Commandre, Opt. Commun. 242, 227 (2004).

3. J. A. Menapace, B. Penetrante, D. Golini, A. Slomba, P. E. Miller, T. Parham, M. Nichols, and J. Peterson, Proc. SPIE 4679, 56 (2002).

4. F. Shi, Y. Shu, Y.-F. Dai, X.-Q. Peng, and S.-Y. Li, Opt. Eng. 52, 9 (2013).

5. D.-P. Zhang, P. Fan, X.-M. Cai, J.-D. Shao, and Z.-X. Fan, Proc. SPIE 6722, 67221Q (2007).

6. E. S. Field, J. C. Bellum, and D. E. Kletecka, Proc. SPIE 9983 998314 (2016).

7. B. Shen, H.-Y. Li, L.-Y. Zhao, and Y.-X. Tang, Proc. SPIE 10255, 102550W (2017).

8. M.-Q. Zhan, T.-Y. Tan, D.-W. Zhang, H.-B. He, J.-D. Shao, and Z.-X. Fan, Proc. SPIE 5774, 365 (2004).

9. E. S. Field, J. C. Bellum, and D. E. Kletecka, Proc. SPIE 9632, 963219 (2015).
10. Y. Xu, D. Wu, Y.-H. Sun, Z.-X. Huang, X.-D. Jiang, X.-F. Wei, Z.-H. Li, B.-Z. Dong, and Z.-H. Wu, Appl. Opt. 44, 527 (2005).

11. T. I. Suratwala, M. L. Hanna, E. L. Miller, P. K. Whitman, I. M. Thomas, P. R. Ehrmann, R. S. Maxwell, and A. K. Burnham, J. Non-Cryst. Solids. 316, 349 (2003).

12. A. L. Rigatti, Proc. SPIE 5647, 136 (2005).

13. X.-G. Li, L.-P. Zou, G.-M. Wu, and J. Shen, Opt. Mater. Express 4, 2478 (2014).

14. F.-T. Chi, L.-H. Yan, H.-B. Lv, C.-C. Wang, and X.-D. Yuan, Thin Solid Films 519, 2483 (2011).

15. L. Zhang, Y. Xu, D. Wu, Y.-H. Sun, X.-D. Jiang, and X.-F. Wei, Opt. Laser Technol. 40, 282 (2008).

16. Y. Wang, Z.-X. Shi, and J. Yin, J. Mater. Chem. 21, 11371 (2011).

17. L. Liu, Y. P. Feng, and Z. X. Shen, Phys. Rev. B 68, 104102 (2003).

18. J.-W. Gu, Q.-Y. Zhang, J. Dang, and C. Xie, Polym. Adv. Technol. 23, 1025 (2012).

19. A. B. Abdellaoui, B. Bouchikhi, and O. Baehr, Mater. Sci. Eng. B 47, 257 (1997).

20. J. D. Ferguson, A. W. Weimer, and S. M. George, Chem. Mater. 12, 3472 (2000).

21. S. Lin, X.-X. Ye, and J. Huang, Phys. Chem. Chem. Phys. 17, 888 (2015).

22. W.-W. Lei, V. N. Mochalin, D. Liu, S. Qin, Y. Gogotsi, and Y. Chen, Nat. Commun. 6, 8 (2015).

23. N. Bazin, J. E. Andrew, and H. A. Mcinnes, J. Sol-Gel Sci. Technol. 13, 757 (1998).

24. K. Sato, H. Horibe, T. Shirai, Y. Hotta, H. Nakano, H. Nagai, K. Mitsuishi, and K. Watari, J. Mater. Chem. 20, 2749 (2010).

25. W.-Y. Zhou, S.-H. Qi, H.-Z. Zhao, and N.-L. Liu, Polym. Compos. 28, 23 (2007).

26. H.-B. Cho, Y. Tokoi, S. Tanaka, H. Suematsu, T. Suzuki, W.-H. Jiang, K. Niihara, and T. Nakayama, Compos. Sci. Technol. 71, 1046 (2011).

27. W.-Y. Zhou, S.-H. Qi, Q.-L. An, H.-Z. Zhao, and N.-L. Liu, Mater. Res. Bull. 42, 1863 (2007).

28. D. S. Williams, J. Appl. Phys. 57, 2340 (1985). 